\title{
Cancers among HIV Infected Patients: A Reason for Routine Screening
}

\author{
Isichei M.W ${ }^{1}$, A .F. Ale ${ }^{1}$, Shitta A.H ${ }^{1}$, Misauno M.A ${ }^{1}$, Isichei C.O ${ }^{2}$ \\ ${ }^{1}$ Department Of Surgery, University Of Jos \\ ${ }^{2}$ Faith Alive Foundation Hospital
}

\begin{abstract}
Human immunodeficiency virus (HIV) has been associated with increased risk of cancer worldwide ${ }^{(I)}$. Despite the proven efficacy of HAART, Death associated with cancer among the HIV infected has therefore remained a big challenge. ${ }^{(2)}$ Cancer screening is a proven effective method of prevention and control in many populations. ${ }^{(16)}$ We analyzed the type of cancers HIV infected patients presented with at some treatment facilities with a view to sensitize health worker to the need for routine cancer screening among HIV infected persons. This is a prospective data collection of HIV infected patients at two major treatment facilities in Plateau state over a three year period January 2013 to January 2016. A total of 343 participants were enrolled, 184(56.4\%) males and 159(46.4\%) females. Majority of reponndants 100(29.1\%) were in the age group 37 - 47years, 83.4\%(286) were married and 244(31.1\%) were unemployed. About 121(35.48\%)95\% of participants CI: 30.45-40.85 had up to primary school education while 20(8.5\%) had no formal education at all CI: 5.86-12.11. The commonest malignancy found among respondents is Kaposi sarcoma 129(37.6\%), followed by breast cancer49(14.3\%), prostate29(8.7\%) and colorectal cancer24(7\%). Cervical cancer and Non Hodgkin's lymphoma were at $16(4.5 \%)$ and $13(3.8 \%)$ respectively. Non AIDS defining cancer is on the increase among HIV infected persons in our community. There is therefore urgent need for routine screening and early detection of cancer among our infected patients.
\end{abstract}

Keywords: HIV/AIDS, Cancer, Defining, Screening

\section{Introduction}

Human immunodeficiency virus (HIV) has been associated with increased risk of cancer worldwide ${ }^{(1)}$. Globally there has been an increase in the cancer incidence with its associated morbidity and mortality but the burden is worse especially in Africa due to the high HIV prevalence. ${ }^{(3)}$ The difference between cancer in the HIV infected person and the non infected is that these cancers run a more aggressive course associated with high morbidity and mortality. ${ }^{(4,5)}$ Cancers associated with HIV infection can be classified as Acquired Immune Deficiency Syndrome(AIDS) defining or Non AIDS defining. A diagnosis of any of the AIDS defining cancers is an infected person indicates progression to AIDS. Kaposi sarcoma, Non Hodgkin's lymphoma and cervical cancer are AIDS defining while non AIDS defining cancer refers to any other cancer other than the three occurring in a HIV infected person. Studies reported on the trend of cancer in a HIV infected person show a decreasing incidences of AIDS defining cancer but an increasing incidence of non AIDS defining cancers. ${ }^{(6)}$ Although the exact mechanism by which HIV infection predisposes an individual to cancer is not well understood, it has been reported to be associated with low immunity and increased viral load. ${ }^{(7)}$

HIV infected individuals have increased risk of developing cancer compared to the general population .${ }^{(8)}$ The introduction of the Highly Active Antiretroviral Therapy(HAART) has improved the once gloomy prognosis of the HIV patients. The stabilized immune system has protected HIV infected persons from common opportunistic infections which used to be the major factor for increased morbidity/mortality and has enabled them to live longer. ${ }^{(9,10)}$ Despite the proven efficacy of HAART, the risk remains high because the immune system function remains impaired in the individuals once infected by HIV. Death associated with cancer among the HIV infected has therefore remained a big challenge. ${ }^{(2)}$ To change the trend of high mortality, there is need for early diagnosis and treatment by doing regular cancer screening when the burden of disease is still low with a high immune system offers a better chance of effective management options. ${ }^{(11)}$

Reports on new HIV infections worldwide show that Sub-Saharan Africa accounts for a large proportion of about $66 \%$ and therefore carries a heavier burden of HIV related cancer compared to other continents. ${ }^{\text {(Nig AIDs control doc) }}$ There has been good improvement in the standard of care as a result of support from partner organization targeting HIV control which has markedly improved survival in infected persons. ${ }^{(12)}$ The dilemma facing the care giver is how to manage the various complications associated with this chronic disease, ranging from drugs related problems to development of co-morbid diseases such as cancer. ${ }^{(13)}$ Although cancer screening is an important component of an ideal HIV management program, it is not routinely done even at comprehensive health centers. ${ }^{15}$ 
Cancer treatment is very expensive and not readily affordable for the majority of patients seen in our health centers with a health care system in Nigeria is mainly "Out of pocket". There are no health centers with standard cancer treatment facilities in the country and even the few with some equipments are often broken down due to over use. There is lack of specialized trained personnel therefore knowledge of cancer among health workers and people living with AIDS in our setting is low. This has lead to very low index of cancer suspicion among care givers and patients who are not sensitized to actively look for signs and symptoms of cancer.

Although there is paucity of knowledge on the true and accurate epidemiology of cancers among HIV infected persons in Nigeria, reports from the few functional site based cancer registries suggest an increasing trend of cancer in Nigeria. The increase in cancer in Nigeria has been reported to be largely due to the high prevalence of HIV infection. ${ }^{(15)}$ There is also a direct increase in Morbidity and Mortality due to delay in seeking treatment for cancer in the general population as well as among the HIV infected patients. ${ }^{(16)}$ Cancer screening is a proven effective method of cancer prevention and control in many populations. ${ }^{(17)}$ The Nigerian HIV treatment guide line includes AIDS defining malignancies as a criteria for staging but cancer screening is absent. Cite The exclusion of routine cancer screening in the HIV program could be a major factor in under diagnosis and reporting of cancer in these group of patients.

The care giver and the patients are not constantly being reminded of the possibility of cancer in this vulnerable group resulting in no active search for it neither do the patients get educated on it to watch out. The key to good outcome in cancer treatment is early detection and control. We analyzed the type of cancers HIV infected patients presented with at some treatment facilities with a view to sensitize health worker to the need for routine cancer screening among HIV infected persons. The findings may be useful in developing preventive programs that will reduce the morbidity and mortality associated with cancer in our HIV infected persons.

\section{Materials and method}

This is a prospective data collection of HIV infected patients at two major treatment facilities in Plateau state over a three year period January 2013 to January 2016. The study was approved by the health and ethics committee of the Faith Alive Foundation Jos. Informed written consent was obtained from the subjects to participate in the study. A structured questionnaire was administered to all infected patients who presented with symptoms of a malignancy. They were followed up till histological diagnosis was obtained then referred for definitive treatment at a tertiary center. Data was obtained on Socio demographics, sign and symptoms patient presented with, duration of current disease, duration of HIV status, CD4 count and HAART combination. Specimen for histological diagnosis was obtained using trucut biopsy needle either direct or image guided depending on the site of tumor; at endoscopy and incision biopsy where indicated. All specimen were subjected to histolopathology, all results negative for malignancy or inconclusive were excluded. Data was entered into Microsoft excel and analyzed using Epi info 3:5.3 software for frequency, proportions, mean and standard deviation. Data summary was done using tables and charts for key indicators.

\section{Results}

A total of 343 participants were enrolled, 184(56.4\%) were males and 159(46.4\%) were females. Majority of reponndants $100(29.1 \%)$ were in the age group 37 - 47years, $83.4 \%(286)$ were married and $244(31.1 \%)$ were unemployed. About $121(35.48 \%) 95 \%$ of participants CI: $30.45-40.85$ had up to primary school education while $20(8.5 \%)$ had no formal education at all CI: 5.86-12.11. The commonest malignancy found among respondents is Kaposi sarcoma 129(37.6\%), followed by breast cancer49(14.3\%), prostate29(8.7\%) and colorectal cancer24(7\%). Cervical cancer and Non Hodgkin's lymphoma were at 16(4.5\%) and $13(3.8 \%)$ respectively.

\section{Discussion}

The main finding in this study was participants presented with both HIV related and non HIV related cancers. Three AIDs defining cancers Kaposi sarcoma ,Cervical cancer and Non Hodgkins Lymphoma were among common cancers found in the participants. The finding of AIDs defining cancers among the participants was not unexpected since it known to be associated with HIV infection. Those who developed AIDs defining cancers had low CD4 cell count and have failed therapy at some point in their treatment. This is similar to the finding of Calabresi, A.et al in Italy where they studied AIDS defining cancers in a cohort of HIV infected patients and compared with uninfected population over a 10 year period. ${ }^{(18)}$ Shiels, M. S had a contrary finding, aging was the main factor for increasing ADCs in there population. ${ }^{(19)}$

The variety of Non AIDs defining cancers we found among the participants was however unexpected. Of the twenty one different types of Non AIDs defining solid tumors among the participants, cancers of the Breast, Prostate, Colorectal, Liver, Nasopharyngx, Squamos cell and Soft tissue sarcoma, were more frequently diagnosed among the participants. Breast cancer was the commonest among the women and Prostate cancer 
among the males. These variety of tumors is consistent being on antiretrovirals for long time and majority of our participants have been on HAART for many years, the longest 22years therefore are at high risk for developing NADC. This finding agrees with the of Brugnaro, $\mathrm{P}$ et al where they found similar malignancies in patients who have been on HAART for two decades. ${ }^{(20)}$ Chao, C. and his colleagues however had a contrary finding, AIDs defining cancer was not associated with first line HAART but rather with the use of protease inhibitors. ${ }^{(21)}$ In our own study we did not link the cancer to the type of ARVs a participant was exposed to.

More males than females participated in the study, this could be because Kaposi Sarcoma and Colon cancer were more frequent in the males. This in agreement with Chapman and colleagues who reported that colon cancer was found to be more common in HIV infected men than women. ${ }^{(22)}$ Franceschi, S. et al found no difference in the incidence of AIDS associated cancers between males and females. ${ }^{(23)}$

Majority of the participants were between the age of 37 to 47 years. HIV infection is known to be common among this active age group in our setting and its put them at high risk of developing cancer. Shiels, M. S et al's findings supports our study, they found cancer that usually occur with advanced age to be occurring among young person's infected with HIV. ${ }^{(24)}$ Crum-Cianflone, $\mathrm{N}$ had a contrary finding in their study, cancer in the HIV infected was associated with increasing age. ${ }^{(25)}$ This could also be related to the age at which persons get infected with HIV in their setting.

\section{Figures and tables}

Table 1: Socio-demographic Characteristics of Patients of HIV infected patients with cancer $(n=344)$

\begin{tabular}{|l|l|l|}
\hline Age Group (years) & Frequency & $\begin{array}{l}\text { Percent } \\
\%\end{array}$ \\
\hline$\leq 25$ & & \\
$26-36$ & 18 & 5.3 \\
$37-47$ & 84 & 24.5 \\
$48-58$ & 100 & 29.1 \\
$59-69$ & 62 & 16.1 \\
$>75$ & 79 & 23.0 \\
\hline Gender & 0 & 0 \\
Male & 184 & 56.6 \\
Female & 159 & 46.4 \\
\hline Marital Status & & \\
Single & 57 & 16.6 \\
Married & 286 & 83.4 \\
\hline Employment status & & \\
Employed & 99 & 28.9 \\
Unemployed & 244 & 31.1 \\
\hline Religion & & \\
Christianity & & 76.9 \\
Islam & 387 & 23.1 \\
\hline Educational Status & 116 & 8.5 \\
None & & 35.5 \\
Primary & 29 & 33.7 \\
Secondary & 121 & 22.3 \\
Tertiary & 115 & \\
\hline
\end{tabular}

Table 2: Type of cancers participants presented with $(n=343)$

\begin{tabular}{|l|l|l|}
\hline Diagnosis & Frequency & Percent \\
\hline Kaposi sarcoma & 129 & 37.6 \\
\hline Breast cancer & 49 & 14.3 \\
\hline Prostate cancer & 29 & 8.5 \\
\hline Colorectal cancer & 24 & 7.0 \\
\hline Cervical cancer & 16 & 4.7 \\
\hline Non Hodgkin's lymphoma & 13 & 3.8 \\
\hline Soft tissue sarcoma & 11 & 3.2 \\
\hline Squamous cell carcinoma & 10 & 2.9 \\
\hline Hepatoma & 9 & 2.6 \\
\hline Nasopharyngeal & 7 & 2.0 \\
\hline Ovarian cancer & 6 & 1.8 \\
\hline Endometrial cancer & 4 & 1.2 \\
\hline Cancer of the head pancreas & 4 & 1.2 \\
\hline Bladder cancer & 4 & 1.2 \\
\hline Renal cancer & 4 & 1.2 \\
\hline Thyroid gland cancer & 4 & 1.2 \\
\hline Salivary gland tumor & 3 & 0.9 \\
\hline
\end{tabular}


Cancers Among HIV Infected Patients: A Reason For Routine Screening

\begin{tabular}{|l|l|l|}
\hline Melanoma & 3 & 0.9 \\
\hline Gastric cancer & 3 & 0.9 \\
\hline Esophageal ca & 3 & 0.9 \\
\hline Testicular tumor & 3 & 0.9 \\
\hline Penile cancer & 2 & 0.6 \\
\hline Bronchogenic cancer & 2 & 0.6 \\
\hline Phylloides & 1 & 0.3 \\
\hline Total & 343 & 100 \\
\hline
\end{tabular}

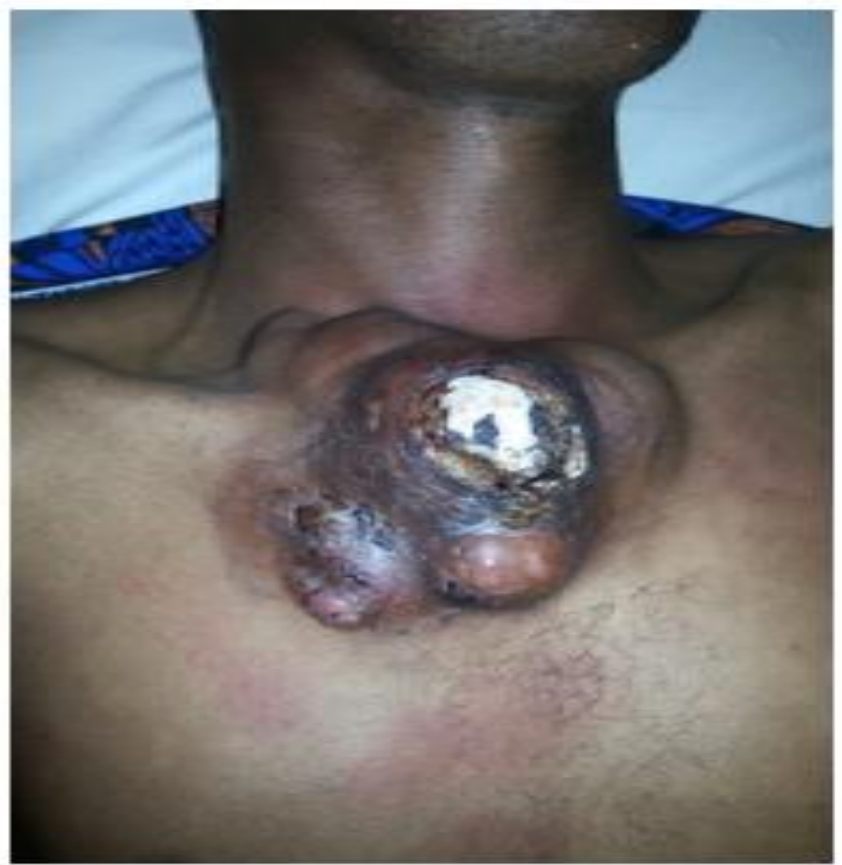

Figure 1. Thyroid cancer in a 32years old man

\section{Conclusion}

We conclude that Non AIDS defining cancer is on the increase among HIV infected persons in our community. Cancer associated with HIV is aggressive and very expensive to treat. There is therefore urgent need for routine screening and early detection of cancer among our infected patients.

\section{References}

[1]. Bibliography. Cancer in AIDS. Current world literature. Current opinion in oncology. 2011;23(5):541-2.

[2]. Alcada J, Taylor MN, Shaw PJ, Janes SM, Navani N, Miller RF. High prevalence of malignancy in HIV-positive patients with mediastinal lymphadenopathy: a study in the era of antiretroviral therapy. Respirology. 2014;19(3):339-45.

[3]. Parkin DM, Sitas F, Chirenje M, Stein L, Abratt R, Wabinga H. Part I: Cancer in Indigenous Africans--burden, distribution, and trends. Lancet Oncol. 2008;9(7):683-92.

[4]. Bourcier V, Winnock M, Ait Ahmed M, Sogni P, Pambrun E, Poizot-Martin I, et al. Primary liver cancer is more aggressive in HIV-HCV coinfection than in HCV infection. A prospective study (ANRS CO13 Hepavih and CO12 Cirvir). Clinics and research in hepatology and gastroenterology. 2012;36(3):214-21.

[5]. Coghill AE, Newcomb PA, Madeleine MM, Richardson BA, Mutyaba I, Okuku F, et al. Contribution of HIV infection to mortality among cancer patients in Uganda. Aids. 2013;27(18):2933-42.

[6]. Cobucci RN, Lima PH, de Souza PC, Costa VV, Cornetta Mda C, Fernandes JV, et al. Assessing the impact of HAART on the incidence of defining and non-defining AIDS cancers among patients with HIV/AIDS: a systematic review. Journal of infection and public health. 2015;8(1):1-10.

[7]. Chen CJ, Hsu WL, Yang HI, Lee MH, Chen HC, Chien YC, et al. Epidemiology of virus infection and human cancer. Recent results in cancer research Fortschritte der Krebsforschung Progres dans les recherches sur le cancer. 2014;193:11-32.

[8]. Deeken JF, Tjen ALA, Rudek MA, Okuliar C, Young M, Little RF, et al. The rising challenge of non-AIDS-defining cancers in HIV-infected patients. Clinical infectious diseases : an official publication of the Infectious Diseases Society of America. 2012;55(9):1228-35.

[9]. Buchacz K, Lau B, Jing Y, Bosch R, Abraham AG, Gill MJ, et al. Incidence of AIDS-Defining Opportunistic Infections in a Multicohort Analysis of HIV-infected Persons in the United States and Canada, 2000-2010. The Journal of infectious diseases. 2016;214(6):862-72.

[10]. Schwarcz L, Chen MJ, Vittinghoff E, Hsu L, Schwarcz S. Declining incidence of AIDS-defining opportunistic illnesses: results from 16 years of population-based AIDS surveillance. Aids. 2013;27(4):597-605.

[11]. Chen CH, Chung CY, Wang LH, Lin C, Lin HL, Lin HC. Risk of cancer among HIV-infected patients from a population-based nested case-control study: implications for cancer prevention. BMC cancer. 2015;15:133.

[12]. Ives NJ, Gazzard BG, Easterbrook PJ. The changing pattern of AIDS-defining illnesses with the introduction of highly active antiretroviral therapy (HAART)in a London clinic. J Infect. 2001;42(2):134-9. 
[13]. Grulich AE, van Leeuwen MT, Falster MO, Vajdic CM. Incidence of cancers in people with HIV/AIDS compared with immunosuppressed transplant recipients: a meta-analysis. Lancet. 2007;370(9581):59-67.

[14]. Jedy-Agba E, Adebamowo C. Knowledge, attitudes and practices of AIDS associated malignancies among people living with HIV in Nigeria. Infect Agent Cancer. 2012;7(1):28.

[15]. Akinwande O, Ogundiran T, Akarolo-Anthony S, Mamadu I, Dakum P, Blattner W, et al. Challenges in treating malignancies in HIV in Nigeria. Curr Opin Oncol. 2009;21(5):455-61.

[16]. Albu E, Reed M, Pathak R, Niazi M, Sivakumar M, Fernandes E, et al. Malignancy in HIV/AIDs: a single hospital experience. Journal of surgical oncology. 2000;75(1):11-8.

[17]. Lopez-Gomez M, Malmierca E, de Gorgolas M, Casado E. Cancer in developing countries: the next most preventable pandemic. The global problem of cancer. Critical reviews in oncology/hematology. 2013;88(1):117-22.

[18]. Calabresi A, Ferraresi A, Festa A, Scarcella C, Donato F, Vassallo F, et al. Incidence of AIDS-defining cancers and virus-related and non-virus-related non-AIDS-defining cancers among HIV-infected patients compared with the general population in a large health district of Northern Italy, 1999-2009. HIV medicine. 2013;14(8):481-90.

[19]. Shiels MS, Engels EA. Evolving epidemiology of HIV-associated malignancies. Current opinion in HIV and AIDS. 2017;12(1):611.

[20]. Brugnaro P, Morelli E, Cattelan F, Petrucci A, Panese S, Eseme F, et al. Non-AIDS definings malignancies among human immunodeficiency virus-positive subjects: Epidemiology and outcome after two decades of HAART era. World journal of virology. 2015;4(3):209-18.

[21]. Chao C, Leyden WA, Xu L, Horberg MA, Klein D, Towner WJ, et al. Exposure to antiretroviral therapy and risk of cancer in HIVinfected persons. AIDS. 2012;26(17):2223-31.

[22]. Chapman C, Aboulafia DM, Dezube BJ, Pantanowitz L. Human immunodeficiency virus-associated adenocarcinoma of the colon: clinicopathologic findings and outcome. Clin Colorectal Cancer. 2009;8(4):215-9.

[23]. Franceschi S, Dal Maso L, Pezzotti P, Polesel J, Braga C, Piselli P, et al. Incidence of AIDS-defining cancers after AIDS diagnosis among people with AIDS in Italy, 1986-1998. J Acquir Immune Defic Syndr. 2003;34(1):84-90.

[24]. Shiels MS, Althoff KN, Pfeiffer RM, Achenbach CJ, Abraham AG, Castilho J, et al. HIV Infection, Immunosuppression, and Age at Diagnosis of Non-AIDS-Defining Cancers. Clinical infectious diseases : an official publication of the Infectious Diseases Society of America. 2016.

[25]. Crum-Cianflone N, Hullsiek KH, Marconi V, Weintrob A, Ganesan A, Barthel RV, et al. Trends in the incidence of cancers among HIV-infected persons and the impact of antiretroviral therapy: a 20-year cohort study. AIDS. 2009;23(1):41-50.

[26]. Special)National guidelines for HIV and AIDS treatment and care in Adolescents and adults Federal ministry of health Abuja nigeria ,October 2010

[27]. [23] Operational guideline- national health insurance scheme, Nigeria. June 2005, nhis

[28]. Joint United Nations Programme on HIV and AIDS, 2015. Joint United Nations Programme on HIV and AIDS Factsheet 2015: Word AIDS Day 2015 